\title{
The Potential of microRNAs for Stem Cell-based Therapy for Degenerative Skeletal Diseases
}

\author{
Emma Budd $^{1} \cdot$ Shona WaddelI ${ }^{1}$ - María C. de Andrés ${ }^{1} \cdot$ Richard O. C. Oreffo $^{1}$
}

Published online: 23 October 2017

(C) The Author(s) 2017. This article is an open access publication

\begin{abstract}
Purpose of Review Degenerative skeletal disorders including osteoarthritis (OA) and osteoporosis (OP) are the result of attenuation of tissue regeneration and lead to painful conditions with limited treatment options. Preventative measures to limit the onset of OA and OP remain a significant unmet clinical need. MicroRNAs (miRNAs) are known to be involved in the differentiation of stem cells, and in combination with stem cell therapy could induce skeletal regeneration and potentially prevent $\mathrm{OA}$ and $\mathrm{OP}$ onset.

Recent Findings The combination of stem cells and miRNA has been successful at regenerating the bone and cartilage in vivo. MiRNAs, including miR-146b known to be involved in chondrogenic differentiation, could provide innovative targets for stem cell-based therapy, for the repair of articular cartilage defects forestalling the onset of OA or in the generation of a stem cell-based therapy for OP.

Summary This review discusses the combination of skeletal stem cells (SSCs) and candidate miRNAs for application in a cell-based therapy approach for skeletal regenerative medicine.
\end{abstract}

Keywords miRNA $\cdot$ Skeletal stem cell $\cdot$ Cartilage $\cdot$ Bone Osteoarthritis $\cdot$ Osteoporosis

Joint first authors are Emma Budd and Shona Waddell.

This article is part of the Topical Collection on Molecular Biology of Skeletal Tissue Engineering

Richard O. C. Oreffo

roco@soton.ac.uk

1 Bone \& Joint Research Group, Centre for Human Development, Stem Cells and Regeneration, Faculty of Medicine, University of Southampton, Southampton SO16 6YD, UK

\section{Introduction}

Degenerative skeletal disorders are specific diseases associated with the ageing bone. These disorders can be divided into two main diseases: osteoarthritis (OA) and osteoporosis (OP). Given OA and OP are the result of the loss of the regenerative capacity of the skeletal tissues, skeletal stem cells (SSCs) have been investigated with the aim of harnessing their potential to improve the symptoms and treatment of these pathologies.

\section{Ageing Cartilage and the Onset of $\mathrm{OA}$}

OA is a prevalent chronic disease and can be described as a heterogeneous condition, which results in joint signs and symptoms associated with defective integrity of the articular cartilage and changes to the bone at joint margins [1]. Articular cartilage is composed of non-migratory and nonproliferative resident chondrocytes embedded within an avascular, alymphatic and aneural specialised extracellular matrix (ECM), factors which following injury are likely to account for the limited capacity of articular cartilage to intrinsically repair [2]. Articular cartilage injury is likely to be causative to the onset of OA. Damage to the articular cartilage may appear asymptomatic but it is extremely likely that over time degenerative changes will result. Messner et al. demonstrated that athletes with isolated chondral lesions did not require treatment following initial injury. However, 14 years later, some of the athletes displayed with a reduction of the joint space, indicating that despite the initial chondral lesions having been asymptomatic, degradation of the articular cartilage supervened leading to permanent knee damage [3]. Cartilage damage is typically succeeded with long-term articular cartilage deterioration and $\mathrm{OA}$.

Articular cartilage deterioration and onset of OA could potentially be prevented by repair of the initial articular cartilage 
defect. A number of research groups have looked to identify the presence of chondroprogenitor cells within the articular cartilage and in tissues directly surrounding the articular cartilage, such as the synovium [4], the groove of Ranvier [5], the intrapatellar fat pad $[6,7]$ and the articular cartilage superficial zone $[8,9]$. However, the source of progenitor populations for articular cartilage repair needs to be readily accessible and must not induce damage to the articular cartilage or tissues during isolation. Harnessing SSCs from bone marrow offers an option which does not involve further damage directly to articular cartilage or any surrounding tissue. The ability to direct bone marrow-derived SSCs to differentiate towards the chondrogenic lineage is a propitious option for articular cartilage regeneration. Thus, exploitation of mechanisms which govern chondrogenic differentiation of human SSCs could have significant implications for methods to induce novel articular cartilage formation and, potentially, help to prevent OA.

\section{Loss of Regenerative Capacity of the Bone and Development of OP}

The human skeleton reaches peak bone mass at around 30 years of age and, thereafter, bone mass is gradually lost. OP is a degenerative skeletal disorder, characterised by low bone mass and generalised disorder of the bone microarchitecture. OP is observed in men and women (in postmenopausal women, exacerbated by a fall in oestrogen production) and is a common cause of loss of bone mass and subsequent fracture [10]. It is estimated that $70 \%$ of inpatient fractures are a consequence of OP [11]. The regenerative capacity of the bone is reduced with age, leading to a decrease in bone mass [12-14]. Bone remodelling and therefore the regenerative potential of the bone is controlled by a careful balance between bone resorption, by osteoclasts, and bone deposition by osteoblasts. In OP, this process of bone remodelling is unbalanced with bone resorption exceeding bone formation resulting in the loss of bone mass observed in OP. The loss of regenerative capacity of the bone is multifactorial including (i) reduced stem cell potency/number, (ii) increased osteoclastic bone resorption, (iii) metabolic/factor imbalance and (iv) reduced osteoblast function [14, 15]. In addition, the increase in bone marrow adiposity is believed to play an important role in OP, with osteoporotic patients exhibiting a higher ratio of adipose tissue to total tissue volume in iliac crest bone biopsies compared to healthy controls $[16,17]$.

Currently, OP is treated with drugs which aim to increase bone density or inhibit bone resorption. Strategies include the use of bisphosphonates $[18,19]$, selective oestrogen receptor modulators [20], calcitonin [21, 22], sodium ranelate [23], RANK ligand inhibitors [24], the recombinant form of parathyroid hormone, teriparatide [25] and, more recently, the antisclerostin antibody, blosozumab [26, 27]. Although these drugs offer significant treatment options, development of efficacious anabolics for an increasing ageing population remains a goal.

\section{Potential for Stem Cells and microRNAs for Treatment of Skeletal Disorders}

Stem cells have been shown to be regulated in part by microRNAs (miRNAs), which regulate genes involved with differentiation post-transcriptionally. MiRNAs are processed from longer primary transcripts which undergo processing in the nucleus and the cytoplasm to form small non-coding RNA, which average 22 nucleotides in length [28]. Sequence complementarity between a miRNA and its target mRNA determines whether the miRNA induces posttranscriptional inhibition or degradation of the mRNA, which in turn prevents translation and protein synthesis [28]. This ability of miRNAs to regulate translation can allow for the potential exploitation of the function of miRNAs for use to control cellular processes including differentiation. Several miRNAs have been identified to play roles in chondrogenesis and osteogenesis [29-31]. MiRNAs found to be involved in these highly regulated processes, could therefore be exploited for their use to either induce stem cell chondrogenic differentiation for articular cartilage regeneration or osteogenic differentiation for bone regeneration. In essence, stem cells could be utilised for the regeneration of skeletal tissues in concert with miRNAs to enhance the differentiation of transplanted stem cells towards the chondrogenic or osteogenic lineages. Use of miRNAs could prime transplanted stem cells, directing them towards the desired cell fate. MiRNA modulation could serve as a tool to enhance stem cell differentiation, a novel approach to articular cartilage tissue reparation and bone regeneration. Not only could this novel concept induce the regeneration of skeletal tissues but, if applied early enough, could prevent the onset and progression of OA and OP. This review will examine the use of stem cells to regenerate skeletal tissue and the discovery of miRNAs which are involved in the chondrogenic and osteogenic differentiation of stem cells, including our own observations. Examples of studies which have demonstrated the use of miRNA modulated stem cell transplantation in vivo are discussed to reinforce the potential of miRNAs to direct stem cells to regenerate skeletal tissues.

\section{The Use of Stem Cells for the Treatment of Degenerative Skeletal Disease}

\section{Properties of Skeletal Stem Cells}

A stem cell is characterised by its ability to self-renew by means of asymmetrical cell division and its potential to differentiate into specialised types of cells, thereby retaining a pool 
of stem cells and simultaneously producing transit amplifying cells [32]. Adult stem cells replace degenerating cells which facilitates tissue homeostasis. Adult stem cells can therefore be defined as the regenerators that follow the degeneration process which may occur due to trauma, age or pathogenic conditions [32].

The term skeletal stem cell (SSC), preferred by the authors and used in this review in reference to our own data defines, specifically, a self-renewing stem cell that resides in postnatal bone marrow and can differentiate into cartilage, the bone, haematopoiesis-supportive stroma and marrow adipocytes. It is the SSC of the bone marrow stroma that is responsible for the regenerative capacity inherent to the bone.

The heterogeneous population of cultured plastic adherent cells isolated from the bone marrow should be referred to as bone marrow stromal cells (BMSCs). However, it is acknowledged, the term mesenchymal stem cell (MSC), originally in reference to a hypothetical common progenitor of a wide range of "mesenchymal" (non-haematopoietic, non-epithelial, mesodermal) tissues, is commonly used and in this review will be retained where cited/used by others in the field.

Additional to their differentiation and proliferative properties, SSCs have been proposed to possess immunomodulatory properties which can regulate tumour evasion, autoimmunity and regulation of transplantation tolerance [33]. A combination of regulatory mechanisms exist within SSCs which act upon several immune cells including dendritic cells, T lymphocytes and natural killer (NK) cells [34]. Tse et al. observed that SSCs failed to stimulate allogeneic peripheral blood mononuclear cells and $\mathrm{T}$ cell proliferation and actively inhibited $\mathrm{T}$ cell proliferation [35]. Le Blanc et al. showed that alloreactive lymphocyte proliferative responses were not elicited in undifferentiated and also osteogenic and chondrogenic differentiated SSCs [36]. The immunosuppressive properties of SSCs, theoretically, limit any rejection of SSCs that could occur during therapeutic cell transplant. The concept that fibroblast-like cells migrate to distal sites of injury was fist hypothesised by the German pathologist Cohnheim [37]. Stem cells have the potential to home to sites of injury where they are likely to induce repair, through direct differentiation to replace damaged cells and/or secretion of mediators, which creates a reparative environment with immunoregulatory function and anti-apoptotic regulation [38].

\section{Therapeutic Potential of SSCs in Degenerative Skeletal Disease}

\section{Osteoarthritis}

Loss of chondrocytes and diminishment of the surrounding specialised ECM is as a result of the inability for cartilage to undergo spontaneous endogenous regeneration. The use of cell-based therapies to repair articular cartilage defects aims to produce a fully functional joint surface, capable of tolerating stress and strain.

Several studies have investigated the potential of SSCs in regenerating cartilage in animal models. For example, Im et al. induced osteochondral defects in to the patella grooves of rabbits, and autologous bone marrow-derived MSCs were applied to the defect sites. Histological and molecular analysis concluded that implantation of cultured MSCs could enhance cartilage repair [39]. In experimentally induced OA joint studies, non-operative administration of MSCs has also shown beneficial effects $[40,41]$. A reduction in the degeneration of articular cartilage was observed following injection of autologous bone marrow-derived MSCs, in a hyaluronan solution, directly into OA-induced caprine knee joints [40].

A popular choice amongst research groups for investigating articular cartilage regeneration has been transplantation of SSCs combined with a scaffold. Previously, osteochondral progenitor cells expanded in vitro and dispersed into a type1 collagen gel were transplanted into a full-thickness surgically induced articular cartilage defect in rabbits. At 24 weeks, the post-implantation subchondral bone was completely repaired with overlying articular cartilage [42]. Furthermore, Berninger et al. have suggested an experimental technique for combining MSCs in fibrin clots, followed by transplantation of pre-established fibrin-cell-clots into osteochondral defects in lapine knee joints. Preliminary experiments observed an intact and homogenous surface 12 weeks following implantation of the fibrin-MSC-clot into defect sites [43].

Previous clinical studies have reported the therapeutic effect of MSCs administration in patients [44-48]. Nejadnik et al. found that patients administered with bone marrow stem cells into chondral lesions demonstrated enhanced physical chondrocyte implantation [44]. Follow-up inspection found that transplantation of autologous expanded bone marrowderived MSCs combined with platelet-rich fibrin glue, to full-thickness cartilage defects in five patients, resulted in improvement to symptoms in all patients. Complete defect filling and surface conformity with native cartilage was observed in three patients [45]. Kuroda et al. showed that administration of autologous bone marrow stromal cells to an articular cartilage defect in a young male athlete resulted in marked improved clinical outcomes. At 7 months post-surgery, arthroscopy revealed that the defect was completely covered with smooth tissues, and histologically the defect was filled with hyalinelike cartilage. Strikingly, 1 year post-surgery, the athlete returned to his previous activity level and experienced no pain with significant improvement in clinical symptoms [48].

\section{Osteoporosis}

Given OP is the result of altered bone remodelling, improving the efficiency or restoration of appropriate balance of this process would appear a natural strategy for the treatment of 
OP. It is known that SSCs can be induced to form osteoblasts when cultured on tissue culture plastic [49]. However, translation to a cell-based treatment requires careful control of the differentiation of the stem cells. This could, potentially, be achieved through the use of miRNAs to control osteogenic differentiation. In addition, ensuring maximal osteogenic differentiation, with minimal differentiation to other lineages, remains a key challenge in translating skeletal stem and progenitor populations from the bench to clinical application. Various strategies have been proposed which would ensure maximal osteogenic lineage commitment. These approaches include selection of a specific stage of osteoprogenitor subsets $[50,51]$. Other approaches to select for osteoprogenitor cells include the use of biomaterials to culture SSCs designed to enhance osteogenic differentiation. Examples of biomaterials include nanosurface geometries $[52,53]$ and osteoconductive scaffolds [54].

The use of bone tissue, autograft (patient derived) and allograft (donor), together with bone stem cells and progenitors has been examined. Marcacci et al., in a study of four patients with large bone defects, examined the potential of autologous culture-expanded SSCs onto a ceramic scaffold [55]. No major complications were reported after surgery and long-term follow-up of 6 to 7 years showed good integration of the scaffold [55]. Kim et al. studied the effect of osteoblast injection into long bone fractures to examine accelerated healing [56]. Autologous osteoblasts were expanded from patients with long bone fracture, and injected into the site of fracture, with the control group receiving no treatment [56]. The results demonstrated that osteoblast injection enhanced fracture healing with little complication [56]. The success of these important, albeit small, trials in humans emphasise the potential of SSC strategies for the treatment of bone fracture, bone defects and potentially degenerative bone diseases. In particular, culturing SSCs with a high osteogenic differentiation potential would prove important to generate the cell numbers required for cell-based therapy [57].

\section{MiRNA Expression During Skeletal Differentiation of Stem Cells}

In vitro models of stem cell differentiation have allowed for the analysis of miRNAs involved with post-transcriptional regulation of chondrocyte and cartilage development, as well as osteocyte and bone development. Such miRNAs are responsible for gene activation or suppression during the process of differentiation. A selection of miRNAs and their mRNA targets studied to date, known to be involved in stem cell differentiation, are listed in Table 1 (chondrogenic differentiation) and Table 2 (osteogenic differentiation) and further illustrated in Fig. 1. Comprehension of miRNA expression profiles and the role that miRNAs play in regulation of gene expression during differentiation of stem cells allows for a better understanding of molecular mechanisms which regulate stem cell differentiation. Critically, miRNAs which influence stem cell fate could be exploited to induce and enhance stem cells, providing a novel cell-based therapy approach. MiRNAs could induce and enhance transplanted stem cells at articular cartilage defect sites to regenerate articular cartilage. MiRNAs could induce and enhance stem cell osteogenic differentiation generating a cell-based therapy for OP treatment. Through the application of miRNA mimics or miRNA inhibitors, stem cell differentiation can be modulated to enhance direction towards the desired lineage. Tables 1 and 2 indicate potential miRNAs of which expression levels could be increased or decreased, using miRNA mimics and miRNA inhibitors, respectively, which could potentially enhance chondrogenic and osteogenic differentiation.

\section{Therapeutic Potential of Modulating miRNAs for Skeletal Disorders}

Given that miRNAs display the potential to regulate chondrogenic and osteogenic differentiation of stem cells, harnessing miRNAs offers an appealing strategy for skeletal tissue repair of cartilage or enhancement of differentiation of SSCs towards an osteogenic lineage for bone formation. The potential of miRNAs to augment articular cartilage regeneration has been demonstrated in a study conducted by Lolli and colleagues [79••]. MiR-221 has been identified as a negative regulator of chondrogenesis $[77,78]$. Lolli et al. have previously shown that silencing miR-221 induced chondrogenic differentiation of hMSCs [78]. hMSCs transfected with an inhibitor of miR-221 were encapsulated in alginate. A cartilage defect in an osteochondral biopsy was then filled with the transfected and alginate encapsulated cells, followed by implantation of the biopsy into immunocompromised mice. Compared to control untreated hMSCs and alginate only controls, miR-221 silenced hMSCs enhanced cartilage repair in vivo and cartilaginous tissue was generated with no sign of hypertrophic associated type X collagen deposition [79]. This approach, combining hMSCs primed with miRNA inhibitor, in an in vivo cartilage defect model is the first of its kind and suggests a translational strategy to localise stem cells to defective cartilage sites and promote cartilage repair.

The potential of miRNAs to augment bone formation has been demonstrated in a number of murine studies. With both miR-138 and miR34a, a hydroxyapatite/tricalcium phosphate (HA/TCP) scaffold was utilised in order to localise stem cells subcutaneously. Chen et al. used a similar approach to study the role of miR-34a, which is a negative regulator of bone formation $[83 \bullet \cdot$. hMSCs were transfected with pre-miR34a, anti-miR-34a and control miR and loaded onto HA/ TCP scaffolds and implanted subcutaneously into 


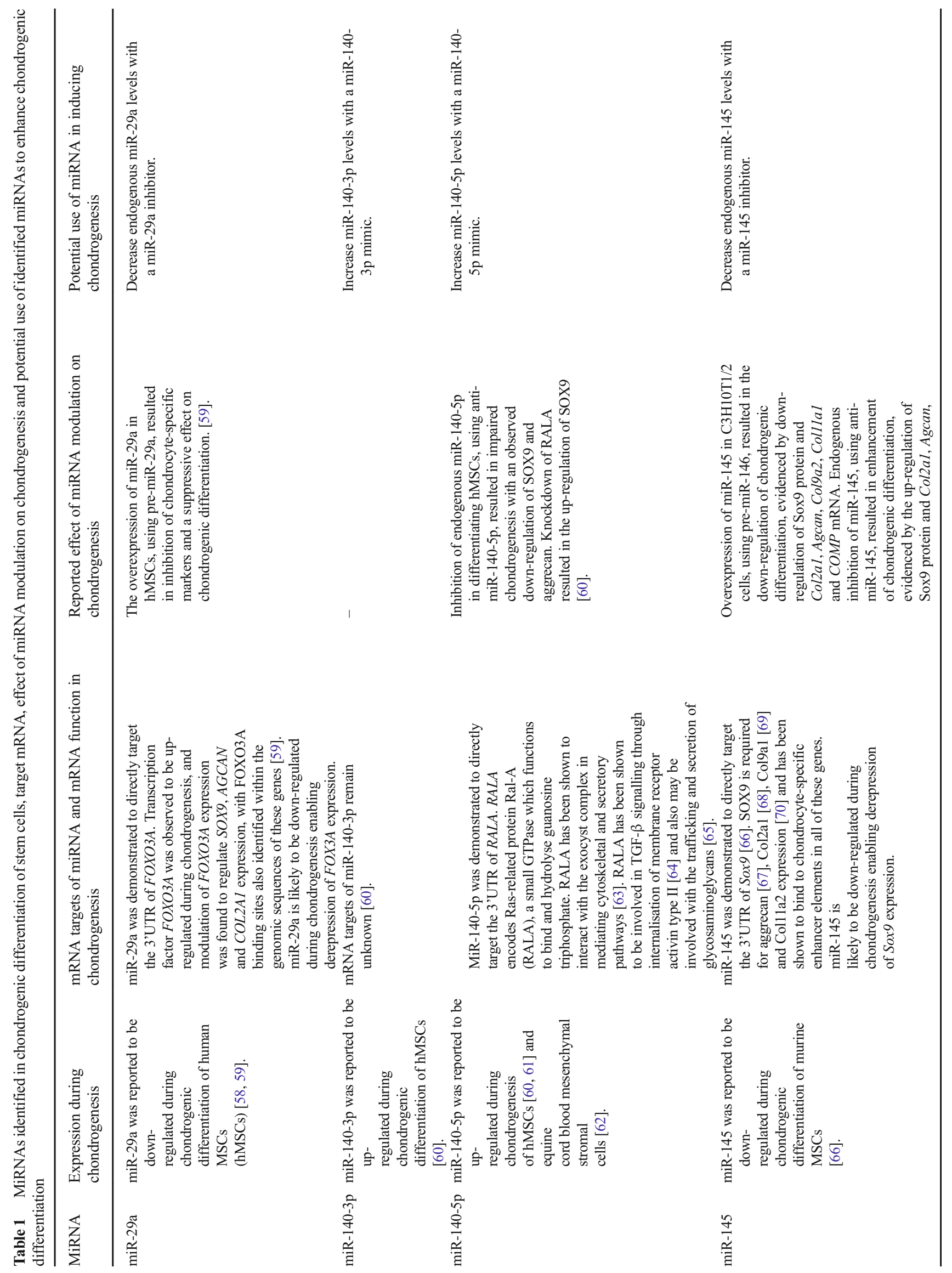




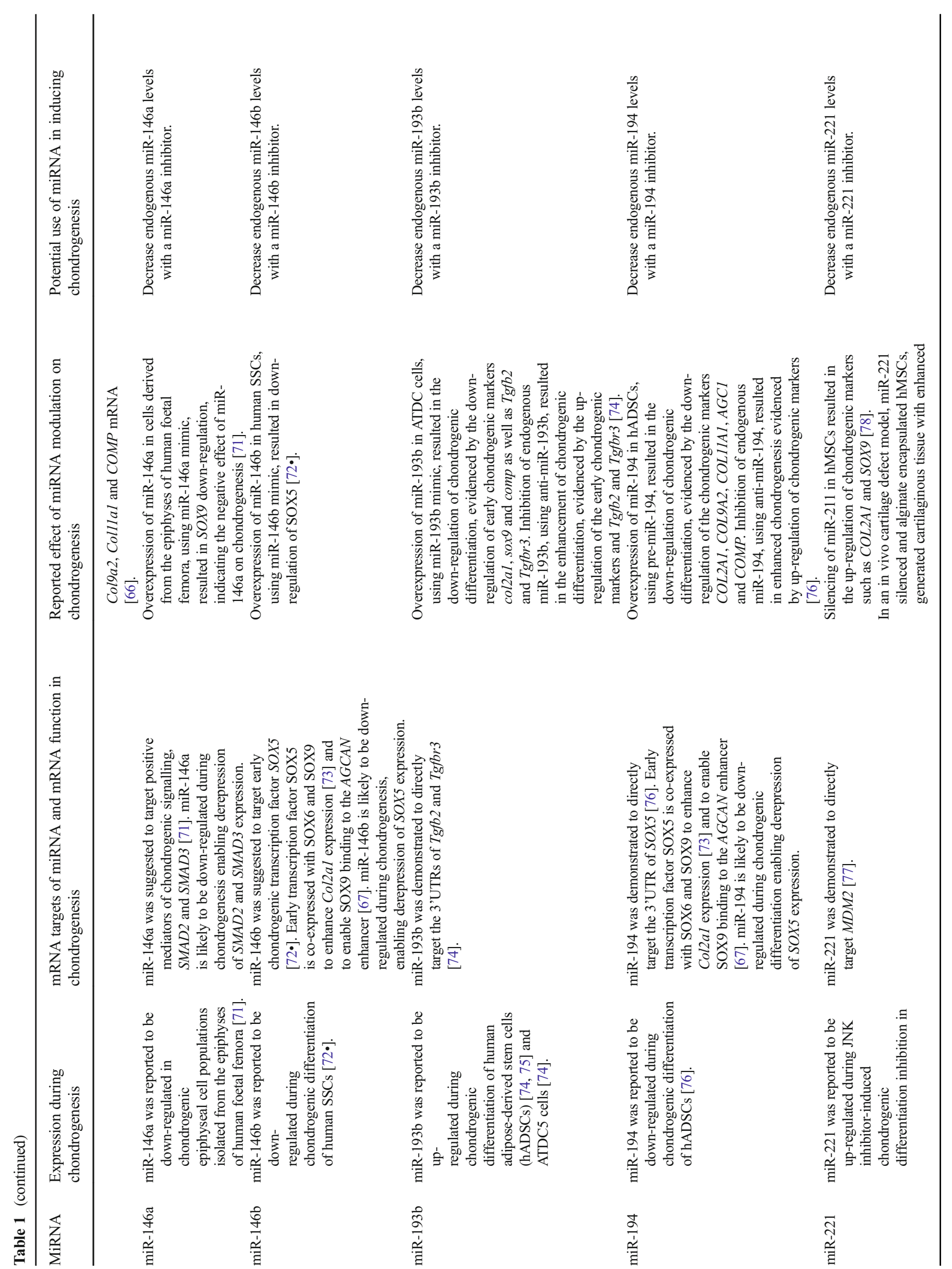




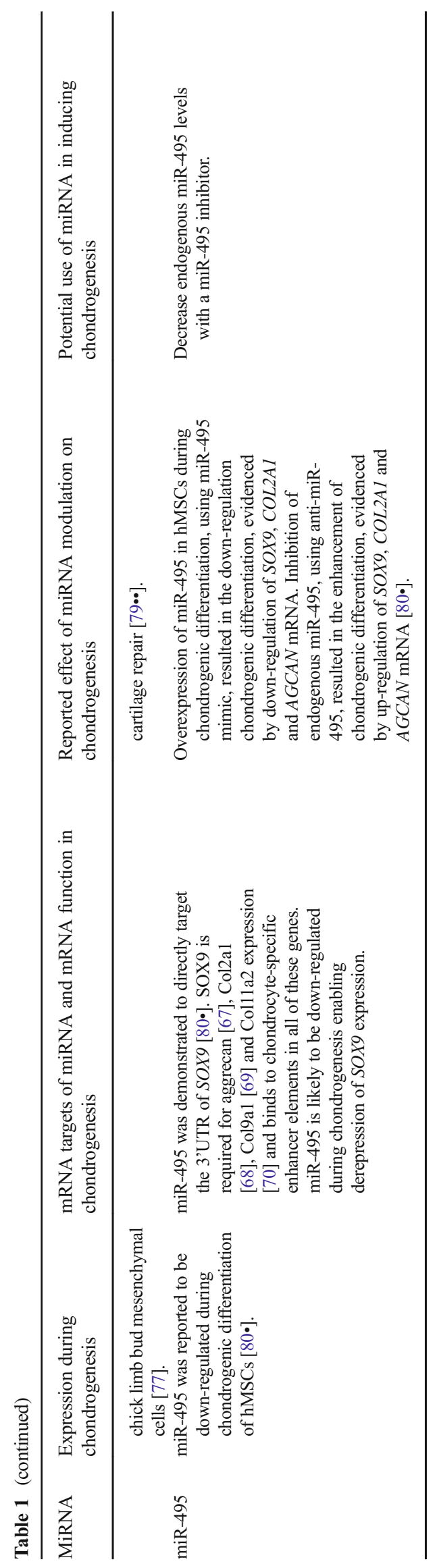

immunocompromised mice. Implantation of the scaffold with hMSCs transfected with anti-miR-34a resulted in a more than 3.5-fold increase in bone formation [83••]. Eskildsen et al. used lipofectamine to transfect pre-miR-138, anti-miR-138 and control miR into hMSCs [84]. The cells were loaded onto HA/TCP scaffold and implanted subcutaneously into immunocompromised mice. Implantation of the scaffold comprising hMSCs transfected with anti-miR-138 resulted in a 2.2fold increase in bone formation. While, implantation of the scaffold comprising hMSCs transfected with miR-138 mimic resulted in a 6.7-fold decrease in bone formation, supporting the observation that miR-138 is a negative regulator of osteogenic differentiation and bone formation [84]. This approach, combining hMSC primed with miRNA inhibitor or mimic and a scaffold, suggests translational strategies to localise stem cells to the bone.

Li et al. used a miRNA intravenous therapy approach, without the use of the scaffold, to investigate the role of the positive regulator of osteogenic differentiation, miR-2861, on bone formation in mice [90]. When antagomiR miR-2861 was intravenously administered to induce miR-2861 silencing, a decrease in femur mineral density and trabecular thickness was observed. Following on from this work, Li et al. studied the role of miR-2681 in the development of OP in human patients with primary OP. The authors identified in a human sibling pair, both suffering from OP, an undetectable expression level of miR-2861 in their bone. A homozygous single nucleotide polymorphism (SNP) in pre-miR-2861 was identified and was suggested to be accountable for negligible miR2861 expression levels and likely to be the confounding factor in the pathogenesis of primary OP. The authors suggest that dysregulation of miR-2861 is likely to induce defective osteoblast differentiation and subsequently contribute to OP. This mutation was found to be heterozygous in the parents of the sibling pair and these family members also suffered from OP. However, when extended to a larger cohort of 369 patients, the same SNP in pre-miR-2861 was not identified, indicating that the SNP was uncommon and not reflective of the general osteoporotic population. Nevertheless, the importance of miR-2861 in osteogenic differentiation and OP was highlighted, indicating its potential as a therapeutic approach.

For successful use of miRNA in stem cell therapeutics, it will be important to localise and minimise any miRNA off target effects. Qureshi et al. developed a technique for photoactivation of nanoparticle conjugated miR-148b [91•]; miR-148b has previously been reported to up-regulate osteogenic differentiation, increasing ALP activity in hMSCs [92]. The non-toxic conjugate remained inert until photoactivation by UV light, which was confirmed by an observed increase in $A L P$ and $O C N$ expression in photoactivated hADSCs compared to non-UV treated cells. In addition, the specific use of nanoparticle conjugated miR-148b resulted in delivery of miR-148b to the intracellular compartments of hADSCs, 


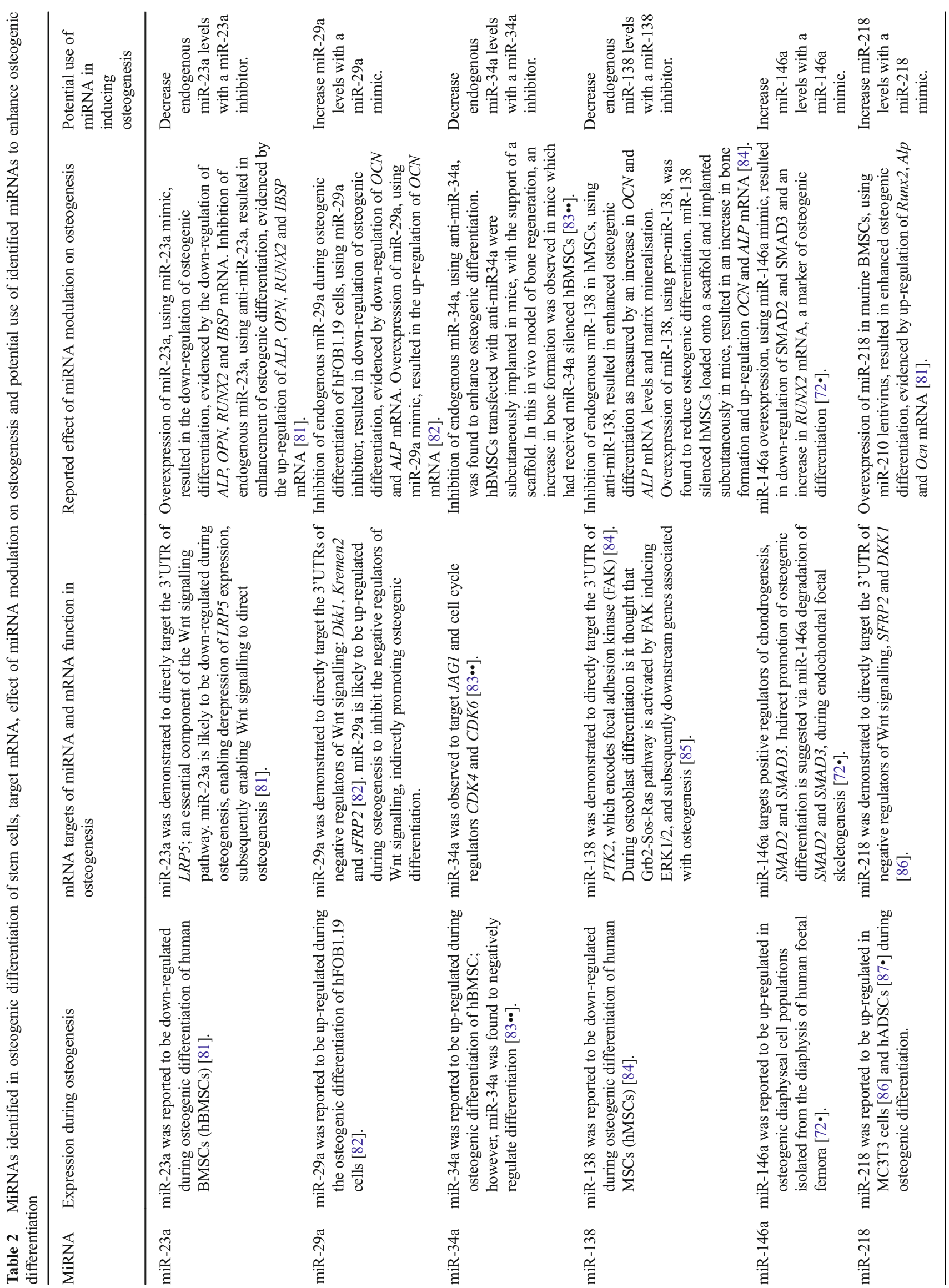




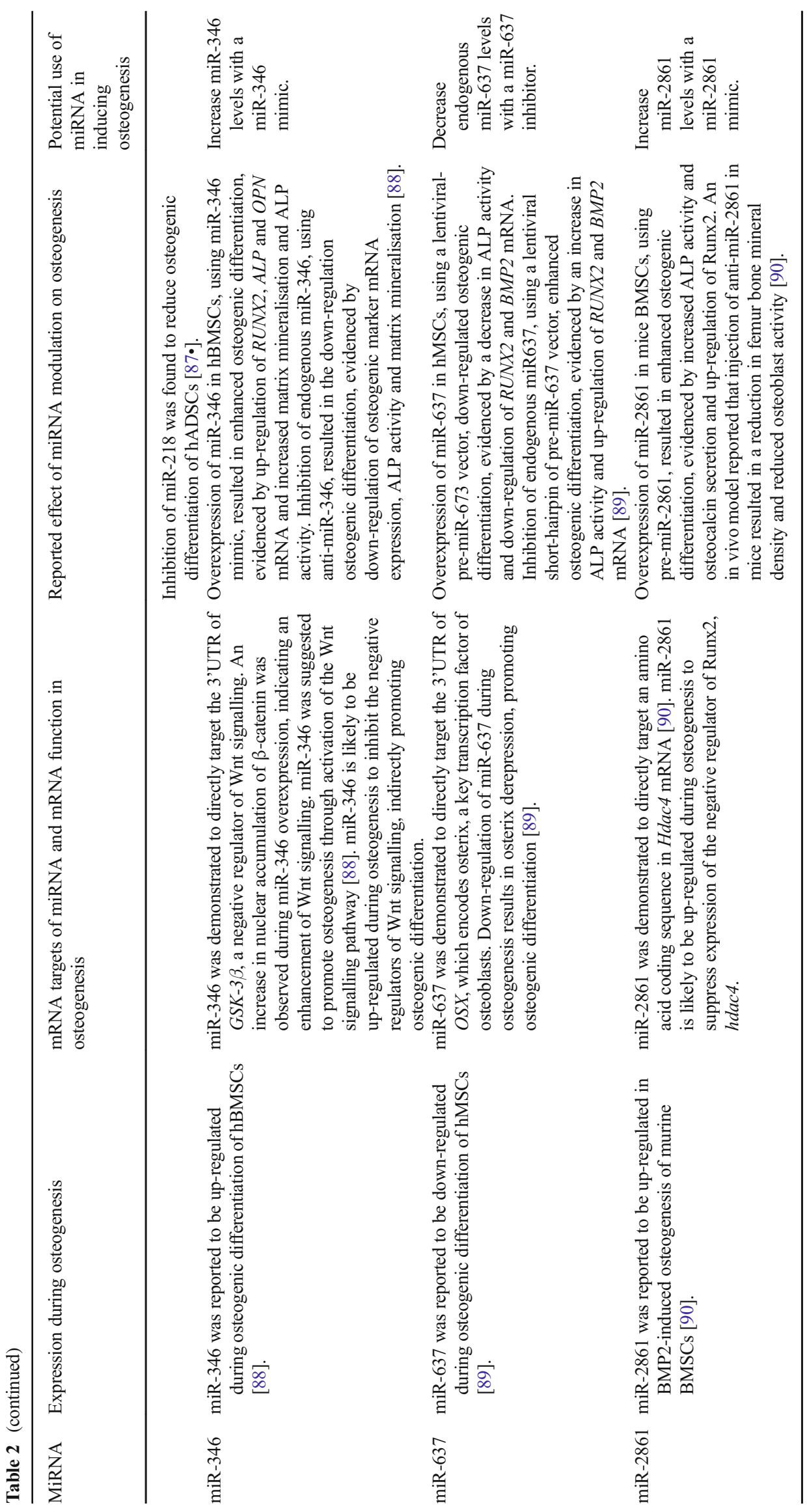


Fig. 1 miRNAs involved in osteogenic and chondrogenic differentiation of SSCs isolated from human bone marrow. Following routine total hip replacement, the femoral head is removed and bone marrow sample donated for isolation of SSCs. From the bone marrow sample, mononuclear cells are isolated by density centrifugation and the cell population enriched for SSCs by magnetic separation. MiRNAs involved in either chondrogenic or osteogenic differentiation are indicated by association with the relevant arrow. MiRNAs in red negatively regulate differentiation and in green positively regulate differentiation

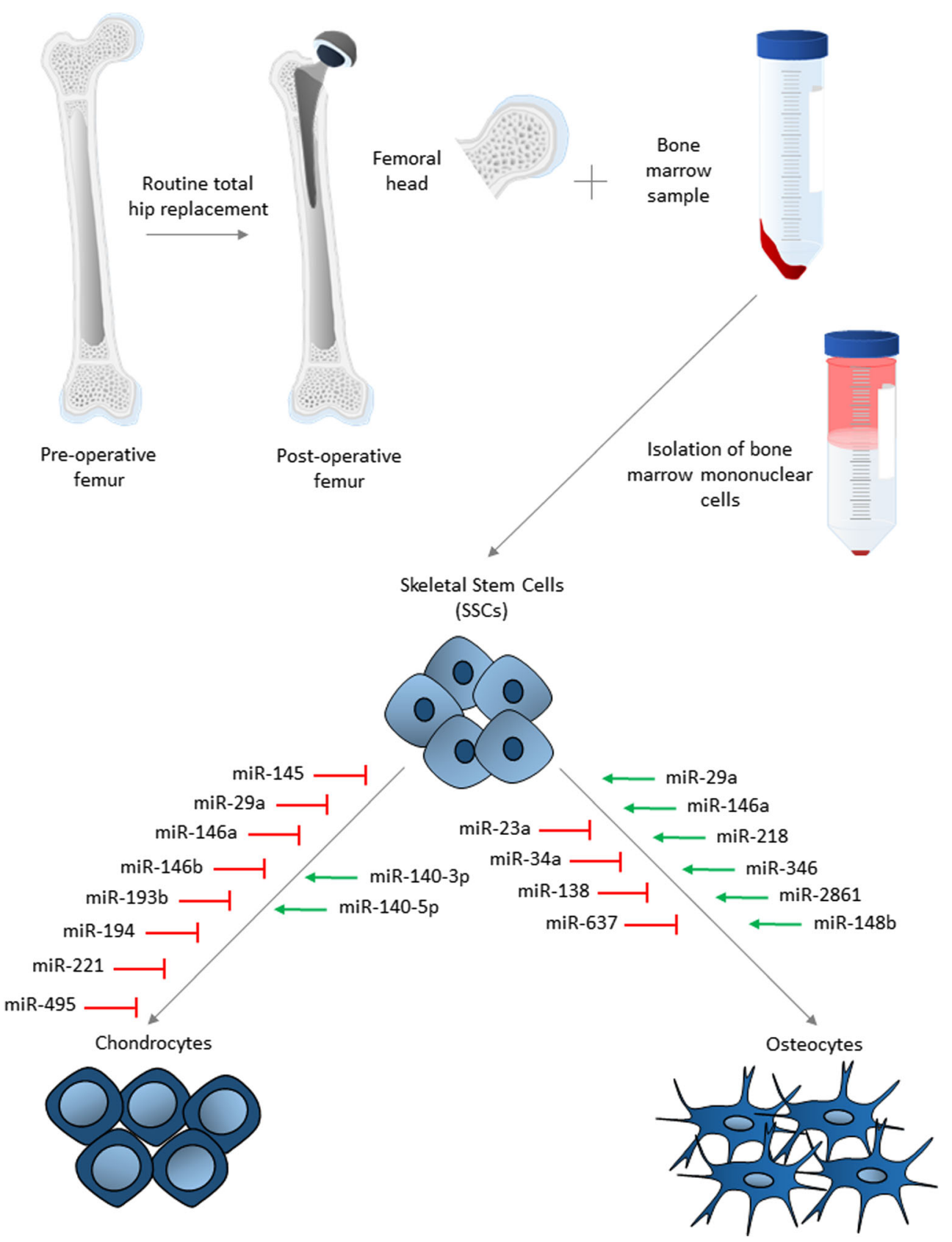

without the need for additional, potentially damaging, chemical-based methods of transfecting stem cells.

\section{Conclusion}

The problems associated with degenerative skeletal disorders highlighted in this review indicate how miRNA could be used to treat these musculoskeletal conditions. The underlying aetiology of OA remains unknown which makes development of a treatment for this debilitating disease difficult. However, if initial chondral lesions can be targeted, the potential for a preventative approach in OA will become a clinical possibility. If the original chondral lesion can be repaired using stem cells enhanced to undergo chondrogenic differentiation efficiently with use of miRNAs modulation, inducing regeneration of the articular cartilage and reinstating integrity, then the degenerative changes, typical of OA could be reduced. Thus, an attractive approach, with knowledge of different miRNAs expression during chondrogenic differentiation, would be to administer specific miRNAs transfected stem cells to chondral defect sites to enhance articular cartilage regeneration capacity. The bone regeneration balance lost in osteoporosis can benefit from an SSC-based cell therapy which could 
potentially restore bone microarchitecture and composition to a healthy state. The approach of priming these SSCs with miRNA could lead to enhanced direction of SSCs towards osteogenic differentiation. MiRNAs have been shown to enhance bone formation in murine trials, and known mutations in miRNAs have been identified in human osteoporotic patients. This cell-based approach could be advantageous when applied at early stages of the disease in order to prevent further bone loss and minimise any potential fracture risk that can occur with disease progression. While consideration of miRNAs in skeletal disease therapy is still in its infancy, with considerable research still to be undertaken, the potential for the use of miRNA in a therapeutic context offers an exciting treatment option for a growing ageing population.

Acknowledgements Work in the authors' laboratories was supported by grants from the BBSRC (BB/L021072/1 and BB/L00609X/1 and UK Regenerative Medicine Platform (MR/K026682/1) and University of Southampton to RO. The work presented here is based on many useful discussions with past and current members of the Bone and Joint Research Group in Southampton, UK.

\section{Compliance with Ethical Standards}

Conflict of Interest Emma Budd, Shona Waddell, María C. de Andrés, and Richard O. C. Oreffo declare that they have no conflicts of interest.

Human and Animal Rights and Informed Consent This article does not contain any studies with human or animal subjects performed by any of the authors.

Open Access This article is distributed under the terms of the Creative Commons Attribution 4.0 International License (http:// creativecommons.org/licenses/by/4.0/), which permits unrestricted use, distribution, and reproduction in any medium, provided you give appropriate credit to the original author(s) and the source, provide a link to the Creative Commons license, and indicate if changes were made.

\section{References}

Papers of particular interest, published recently, have been highlighted as:

- Of importance

•- Of major importance

1. Sarzi-Puttini P, Cimmino MA, Scarpa R, Caporali R, Parazzini F, Zaninelli A, et al. Osteoarthritis: an overview of the disease and its treatment strategies. Semin Arthritis Rheum. 2005;35(1 Suppl 1):110.

2. Sophia Fox AJ, Bedi A, Rodeo SA. The basic science of articular cartilage: structure, composition, and function. Sports Health. 2009;1(6):461-8.

3. Messner K, Maletius W. The long-term prognosis for severe damage to weight-bearing cartilage in the knee: a 14-year clinical and radiographic follow-up in 28 young athletes. Acta Orthop Scand. 1996;67(2):165-8.
4. De Bari C, Dell'Accio F, Tylzanowski P, Luyten FP. Multipotent mesenchymal stem cells from adult human synovial membrane. Arthritis Rheum. 2001;44(8):1928-42.

5. Karlsson C, Thornemo M, Henriksson HB, Lindahl A. Identification of a stem cell niche in the zone of Ranvier within the knee joint. J Anat. 2009;215(3):355-63.

6. Wickham MQ, Erickson GR, Gimble JM, Vail TP, Guilak F. Multipotent stromal cells derived from the infrapatellar fat pad of the knee. Clin Orthop Relat Res. 2003;412:196-212.

7. Candela ME, Yasuhara R, Iwamoto M, Enomoto-Iwamoto M. Resident mesenchymal progenitors of articular cartilage. Matrix Biol : J Int Soc Matrix Biol. 2014;39:44-9.

8. Dowthwaite GP, Bishop JC, Redman SN, Khan IM, Rooney P, Evans DJR, et al. The surface of articular cartilage contains a progenitor cell population. J Cell Sci. 2004;117(6):889-97.

9. Hattori S, Oxford C, Reddi AH. Identification of superficial zone articular chondrocyte stem/progenitor cells. Biochem Biophys Res Commun. 2007;358(1):99-103.

10. Szulc P, Delmas PD. Bone loss in elderly men: increased endosteal bone loss and stable periosteal apposition. The prospective MINOS study. Osteoporos Int. 2007;18(4):495-503.

11. Court-Brown CM, Caesar B. Epidemiology of adult fractures: a review. Injury. 2006;37(8):691-7.

12. Stenderup K, Justesen J, Clausen C, Kassem M. Aging is associated with decreased maximal life span and accelerated senescence of bone marrow stromal cells. Bone. 2003;33(6):919-26.

13. Nishida S, Endo N, Yamagiwa H, Tanizawa T, Takahashi HE. Number of osteoprogenitor cells in human bone marrow markedly decreases after skeletal maturation. J Bone Miner Metab. 1999;17(3):171-7.

14. Rodriguez JP, Garat S, Gajardo H, Pino AM, Seitz G. Abnormal osteogenesis in osteoporotic patients is reflected by altered mesenchymal stem cells dynamics. J Cell Biochem. 1999;75(3):414-23.

15. Caplan AI. Mesenchymal stem cells: cell-based reconstructive therapy in orthopedics. Tissue Eng. 2005;11(7-8):1198-211.

16. Justesen J, Stenderup K, Ebbesen EN, Mosekilde L, Steiniche T, Kassem M. Adipocyte tissue volume in bone marrow is increased with aging and in patients with osteoporosis. Biogerontology. 2001;2(3):165-71.

17. Verma S, Rajaratnam JH, Denton J, Hoyland JA, Byers RJ. Adipocytic proportion of bone marrow is inversely related to bone formation in osteoporosis. J Clin Pathol. 2002;55(9):693-8.

18. Drake MT, Clarke BL, Khosla S. Bisphosphonates: mechanism of action and role in clinical practice. Mayo Clin Proc. 2008;83(9): $1032-45$.

19. Brumsen C, Papapoulos SE, Lips P, Geelhoed-Duijvestijn P, Hamdy NAT, Landman JO, et al. Daily oral pamidronate in women and men with osteoporosis: a 3-year randomized placebocontrolled clinical trial with a 2-year open extension. J Bone Miner Res. 2002;17(6):1057-64.

20. Reginster JY, Ferrari S, Hadji P. Current challenges in the treatment of osteoporosis: an opportunity for bazedoxifene. Curr Med Res Opin. 2014;30(6):1165-76.

21. Binkley N, Bolognese M, Sidorowicz-Bialynicka A, Vally T, Trout $\mathrm{R}$, Miller C, et al. A phase 3 trial of the efficacy and safety of oral recombinant calcitonin: the Oral Calcitonin in Postmenopausal Osteoporosis (ORACAL) trial. J Bone Miner Res. 2012;27(8): 1821-9.

22. Rizzoli R, Sigaud A, Azria M, Herrmann FR. Nasal salmon calcitonin blunts bone microstructure alterations in healthy postmenopausal women. Osteoporos Int. 2015;26(1):383-93.

23. Reginster JY, Brandi ML, Cannata-Andia J, Cooper C, Cortet B, Feron JM, et al. The position of strontium ranelate in today's management of osteoporosis. Osteoporos Int. 2015;26(6):1667-71. 
24. Sutton EE, Riche DM. Denosumab, a RANK ligand inhibitor, for postmenopausal women with osteoporosis. Ann Pharmacother. 2012;46(7-8):1000-9.

25. Lindsay R, Krege JH, Marin F, Jin L, Stepan JJ. Teriparatide for osteoporosis: importance of the full course. Osteoporosis. 2016;27(8):2395-410.

26. Clarke BL. Anti-sclerostin antibodies: utility in treatment of osteoporosis. Maturitas. 2014;78(3):199-204.

27. Recker RR, Benson CT, Matsumoto T, Bolognese MA, Robins DA, Alam J, et al. A randomized, double-blind phase 2 clinical trial of blosozumab, a sclerostin antibody, in postmenopausal women with low bone mineral density. J Bone Miner Res. 2015;30(2):216-24.

28. Pasquinelli AE, Hunter S, Bracht J. MicroRNAs: a developing story. Curr Opin Genet Dev. 2005;15(2):200-5.

29. Wu C, Tian B, Qu X, Liu F, Tang T, Qin A, et al. MicroRNAs play a role in chondrogenesis and osteoarthritis (review). Int J Mol Med. 2014;34(1):13-23.

30. Fang S, Deng Y, Gu P, Fan X. MicroRNAs regulate bone development and regeneration. Int J Mol Sci. 2015;16(4):8227-53.

31. Zhao X, Xu D, Li Y, Zhang J, Liu T, Ji Y, et al. MicroRNAs regulate bone metabolism. J Bone Miner Metab. 2014;32(3):221-31.

32. Weiner L. Definitions and criteria for stem cells. In: Weiner L, editor. Neural stem cells. Methods in molecular biology ${ }^{\mathrm{TM}}$, vol. 438. New York: Humana Press; 2008. p. 3-8.

33. Chen X, Armstrong MA, Li G. Mesenchymal stem cells in immunoregulation. Immunol Cell Biol. 2006;84(5):413-21.

34. Chen P-M, Yen M-L, Liu K-J, Sytwu H-K, Yen B-L. Immunomodulatory properties of human adult and fetal multipotent mesenchymal stem cells. J Biomed Sci. 2011;18(1):49.

35. Tse WT, Pendleton JD, Beyer WM, Egalka MC, Guinan EC. Suppression of allogeneic T-cell proliferation by human marrow stromal cells: implications in transplantation. Transplantation. 2003;75(3):389-97.

36. Le Blanc K, Tammik C, Rosendahl K, Zetterberg E, Ringden O. HLA expression and immunologic properties of differentiated and undifferentiated mesenchymal stem cells. Exp Hematol. 2003;31(10):890-6.

37. Cohnheim J. Ueber Entzündung und Eiterung. Archiv Pathol Anat Physiol Klin Med. 40(1):1-79.

38. Sordi V, Malosio ML, Marchesi F, Mercalli A, Melzi R, Giordano $\mathrm{T}$, et al. Bone marrow mesenchymal stem cells express a restricted set of functionally active chemokine receptors capable of promoting migration to pancreatic islets. Blood. 2005;106(2):419-27.

39. Im GI, Kim DY, Shin JH, Hyun CW, Cho WH. Repair of cartilage defect in the rabbit with cultured mesenchymal stem cells from bone marrow. J Bone Joint Surg Br Vol. 2001;83(2):289-94.

40. Murphy JM, Fink DJ, Hunziker EB, Barry FP. Stem cell therapy in a caprine model of osteoarthritis. Arthritis Rheum. 2003;48(12): 3464-74.

41. Al Faqeh H, Nor Hamdan BM, Chen HC, Aminuddin BS, Ruszymah BH. The potential of intra-articular injection of chondrogenic-induced bone marrow stem cells to retard the progression of osteoarthritis in a sheep model. Exp Gerontol. 2012;47(6):458-64.

42. Wakitani S, Goto T, Pineda SJ, Young RG, Mansour JM, Caplan AI, et al. Mesenchymal cell-based repair of large, full-thickness defects of articular cartilage. J Bone Joint Surg Am. 1994;76(4): 579-92.

43. Berninger MT, Wexel G, Rummeny EJ, Imhoff AB, Anton M, Henning TD, et al. Treatment of osteochondral defects in the rabbit's knee joint by implantation of allogeneic mesenchymal stem cells in fibrin clots. J Vis Exp: JoVE. 2013(75):4423.

44. Nejadnik H, Hui JH, Feng Choong EP, Tai BC, Lee EH. Autologous bone marrow-derived mesenchymal stem cells versus autologous chondrocyte implantation: an observational cohort study. Am J Sports Med. 2010;38(6):1110-6.
45. Haleem AM, Singergy AAE, Sabry D, Atta HM, Rashed LA, Chu $\mathrm{CR}$, et al. The clinical use of human culture-expanded autologous bone marrow mesenchymal stem cells transplanted on platelet-rich fibrin glue in the treatment of articular cartilage defects: a pilot study and preliminary results. Cartilage. 2010;1(4):253-61.

46. Kasemkijwattana C, Hongeng S, Kesprayura S, Rungsinaporn V, Chaipinyo K, Chansiri K. Autologous bone marrow mesenchymal stem cells implantation for cartilage defects: two cases report. J Med Assoc Thai = Chotmaihet Thangphaet. 2011;94(3):395-400.

47. Davatchi F, Abdollahi BS, Mohyeddin M, Shahram F, Nikbin B. Mesenchymal stem cell therapy for knee osteoarthritis. Preliminary report of four patients. Int J Rheum Dis. 2011;14(2):211-5.

48. Kuroda R, Ishida K, Matsumoto T, Akisue T, Fujioka H, Mizuno K, et al. Treatment of a full-thickness articular cartilage defect in the femoral condyle of an athlete with autologous bone-marrow stromal cells. Osteoarthr Cartil / OARS, Osteoar Res Soc. 2007;15(2):22631 .

49. Abdallah BM, Jafari A, Zaher W, Qiu W, Kassem M. Skeletal (stromal) stem cells: an update on intracellular signaling pathways controlling osteoblast differentiation. Bone. 2015;70:28-36.

50. Loebel C, Czekanska EM, Bruderer M, Salzmann G, Alini M, Stoddart MJ. In vitro osteogenic potential of human mesenchymal stem cells is predicted by Runx $2 / \operatorname{Sox} 9$ ratio. Tissue Eng A. 2015;21(1-2):115-23.

51. Born AK, Lischer S, Maniura-Weber K. Watching osteogenesis: life monitoring of osteogenic differentiation using an osteocalcin reporter. J Cell Biochem. 2012;113(1):313-21.

52. Dalby MJ, Gadegaard N, Tare R, Andar A, Riehle MO, Herzyk P, et al. The control of human mesenchymal cell differentiation using nanoscale symmetry and disorder. Nat Mater. 2007;6(12):9971003.

53. Kilian KA, Bugarija B, Lahn BT, Mrksich M. Geometric cues for directing the differentiation of mesenchymal stem cells. Proc Natl Acad Sci U S A. 2010;107(11):4872-7.

54. Thibault RA, Baggett LS, Mikos AG, Kasper FK. Osteogenic differentiation of mesenchymal stem cells on pregenerated extracellular matrix scaffolds in the absence of osteogenic cell culture supplements. Tissue Eng A. 2010;16(2):431-40.

55. Marcacci M, Kon E, Moukhachev V, Lavroukov A, Kutepov S, Quarto R, et al. Stem cells associated with macroporous bioceramics for long bone repair: 6- to 7-year outcome of a pilot clinical study. Tissue Eng. 2007;13(5):947-55.

56. Kim SJ, Shin YW, Yang KH, Kim SB, Yoo MJ, Han SK, et al. A multi-center, randomized, clinical study to compare the effect and safety of autologous cultured osteoblast (Ossron) injection to treat fractures. BMC Musculoskelet Disord. 2009;10:20.

57. Jones EA, Giannoudis PV, Kouroupis D. Bone repair with skeletal stem cells: rationale, progress to date and clinical application. Ther Adv Musculoskelet Dis. 2016;8(3):57-71.

58. Guérit D, Philipot D, Brondello J-M, Chuchana P, Jorgensen C, Noël D. Inhibitory effect of miR-29A on the chondrogenic differentiation of mesenchymal stem cells. Osteoarthr Cartil. 2012;20: S52.

59. Guerit D, Brondello JM, Chuchana P, Philipot D, Toupet K, Bony $\mathrm{C}$, et al. FOXO3A regulation by miRNA-29a controls chondrogenic differentiation of mesenchymal stem cells and cartilage formation. Stem Cells Dev. 2014;23(11):1195-205.

60. Karlsen TA, Jakobsen RB, Mikkelsen TS, Brinchmann JE. microRNA-140 targets RALA and regulates chondrogenic differentiation of human mesenchymal stem cells by translational enhancement of SOX9 and ACAN. Stem Cells Dev. 2014;23(3): 290-304.

61. Miyaki S, Nakasa T, Otsuki S, Grogan SP, Higashiyama R, Inoue A, et al. MicroRNA-140 is expressed in differentiated human articular chondrocytes and modulates interleukin-1 responses. Arthritis Rheum. 2009;60(9):2723-30. 
62. Buechli ME, Lamarre J, Koch TG. MicroRNA-140 expression during chondrogenic differentiation of equine cord blood-derived mesenchymal stromal cells. Stem Cells Dev. 2013;22(8):1288-96.

63. Sugihara K, Asano S, Tanaka K, Iwamatsu A, Okawa K, Ohta Y. The exocyst complex binds the small GTPase RalA to mediate filopodia formation. Nat Cell Biol. 2002;4(1):73-8.

64. Matsuzaki T, Hanai S, Kishi H, Liu Z, Bao Y, Kikuchi A, et al. Regulation of endocytosis of activin type II receptors by a novel PDZ protein through Ral/Ral-binding protein 1-dependent pathway. J Biol Chem. 2002;277(21):19008-18.

65. Wang L, Li G, Sugita S. RalA-exocyst interaction mediates GTPdependent exocytosis. J Biol Chem. 2004;279(19):19875-81.

66. Yang B, Guo H, Zhang Y, Chen L, Ying D, Dong S. MicroRNA145 regulates chondrogenic differentiation of mesenchymal stem cells by targeting Sox9. PLoS One. 2011;6(7):e21679.

67. Han Y, Lefebvre V. L-Sox 5 and Sox 6 drive expression of the aggrecan gene in cartilage by securing binding of Sox 9 to a farupstream enhancer. Mol Cell Biol. 2008;28(16):4999-5013.

68. Bell DM, Leung KK, Wheatley SC, Ng LJ, Zhou S, Ling KW, et al. SOX9 directly regulates the type-II collagen gene. Nat Genet. 1997;16(2):174-8

69. Zhang P, Jimenez SA, Stokes DG. Regulation of human COL9A1 gene expression. Activation of the proximal promoter region by SOX9. J Biol Chem. 2003;278(1):117-23.

70. Liu Y, Li H, Tanaka K, Tsumaki N, Yamada Y. Identification of an enhancer sequence within the first intron required for cartilagespecific transcription of the alpha2(XI) collagen gene. J Biol Chem. 2000;275(17):12712-8.

71. Cheung KS, Sposito N, Stumpf PS, Wilson DI, Sanchez-Elsner T, Oreffo RO. MicroRNA-146a regulates human foetal femur derived skeletal stem cell differentiation by down-regulating SMAD2 and SMAD3. PLoS One. 2014;9(6):e98063.

72. Budd E, de Andres MC, Sanchez-Elsner T, Oreffo ROC. MiR-146b is down-regulated during the chondrogenic differentiation of human bone marrow derived skeletal stem cells and up-regulated in osteoarthritis. Sci Rep. 2017;7:11. This study demonstrates dysregulation of miR-146b in osteoarthritic chondrocytes and thereby illustrating importance of controlling miRNA to treat OA.

73. Lefebvre V, Li P, de Crombrugghe B. A new long form of Sox5 (LSox5), Sox6 and Sox 9 are coexpressed in chondrogenesis and cooperatively activate the type II collagen gene. EMBO J. 1998;17(19):5718-33.

74. Hou C, Yang Z, Kang Y, Zhang Z, Fu M, He A, et al. MiR-193b regulates early chondrogenesis by inhibiting the TGF-beta2 signaling pathway. FEBS Lett. 2015;589(9):1040-7.

75. Zhang Z, Kang Y, Zhang Z, Zhang H, Duan X, Liu J, et al. Expression of microRNAs during chondrogenesis of human adipose-derived stem cells. Osteoarthr Cartil / OARS, Osteoarthr Res Soc. 2012;20(12):1638-46.

76. Xu J, Kang Y, Liao W-M, Yu L. MiR-194 regulates chondrogenic differentiation of human adipose-derived stem cells by targeting Sox5. PLoS One. 2012;7(3):e31861.

77. Kim D, Song J, Jin E-J. MicroRNA-221 regulates chondrogenic differentiation through promoting proteosomal degradation of slug by targeting Mdm2. J Biol Chem. 2010;285(35):26900-7.

78. Lolli A, Lambertini E, Penolazzi L, Angelozzi M, Morganti C, Franceschetti T, et al. Pro-chondrogenic effect of miR-221 and slug depletion in human MSCs. Stem Cell Rev. 2014;10(6):841-55.

79.• Lolli A, Narcisi R, Lambertini E, Penolazzi L, Angelozzi M, Kops $\mathrm{N}$, et al. Silencing of antichondrogenic microRNA-221 in human mesenchymal stem cells promotes cartilage repair in vivo. Stem Cells. 2016;34(7):1801-11. This study demonstrates the first published use of miRNA silenced stem cells to successfully induce cartilage regeneration in vivo.

80. Lee S, Yoon DS, Paik S, Lee KM, Jang Y, Lee JW. microRNA-495 inhibits chondrogenic differentiation in human mesenchymal stem cells by targeting Sox9. Stem Cells Dev. 2014;23(15):1798-808. This study demonstrates miRNA-459 altering chondrogenic differentation of hMSCs through the targeting of master regulator Sox9.

81. Li T, Li HL, Wang YZ, Li TP, Fan JF, Xiao K, et al. microRNA-23a inhibits osteogenic differentiation of human bone marrow-derived mesenchymal stem cells by targeting LRP5. Int J Biochem Cell Biol. 2016;72:55-62.

82. Kapinas K, Kessler C, Ricks T, Gronowicz G, Delany AM. miR-29 modulates Wnt signaling in human osteoblasts through a positive feedback loop. J Biol Chem. 2010;285(33):25221-31.

83.• Chen L, Holmstrom K, Qiu W, Ditzel N, Shi K, Hokland L, et al. MicroRNA-34a inhibits osteoblast differentiation and in vivo bone formation of human stromal stem cells. Stem Cells (Dayton, Ohio). 2014;32(4):902-12. The authors used a murine preclinical model of heterotopic bone formation in which hMSCs transfected with anti-miR-34 in combination with a scaffold resulted in a positive effect in bone formation. This demonstrates potential use for miRNA/SSC in clinical therapeutics.

84. Eskildsen T, Taipaleenmaki H, Stenvang J, Abdallah BM, Ditzel N, Nossent AY, et al. MicroRNA-138 regulates osteogenic differentiation of human stromal (mesenchymal) stem cells in vivo. Proc Natl Acad Sci U S A. 2011;108(15):6139-44.

85. Salasznyk RM, Klees RF, Williams WA, Boskey A, Plopper GE. Focal adhesion kinase signaling pathways regulate the osteogenic differentiation of human mesenchymal stem cells. Exp Cell Res. 2007;313(1):22-37.

86. Hassan MQ, Maeda Y, Taipaleenmaki H, Zhang W, Jafferji M, Gordon JA, et al. miR-218 directs a Wnt signaling circuit to promote differentiation of osteoblasts and osteomimicry of metastatic cancer cells. J Biol Chem. 2012;287(50):42084-92.

87. Zhang WB, Zhong WJ, Wang L. A signal-amplification circuit between miR-218 and Wnt/beta-catenin signal promotes human adipose tissue-derived stem cells osteogenic differentiation. Bone. 2014;58:59-66. This study demonstrates a relationship between the osteogenesis promoting miR-218, and the osteogenesis promoting Wnt/beta-catenin signalling network. Exploiting this relationship could have implications in miRNA therapies.

88. Wang Q, Cai J, Cai X-H, Lei C. miR-346 regulates osteogenic differentiation of human bone marrow-derived mesenchymal stem cells by targeting the Wnt/B-catenin pathway. PLoS One. 2013;8(9):1-8.

89. Zhang JF, Fu WM, He ML, Wang H, Wang WM, Yu SC, et al. MiR637 maintains the balance between adipocytes and osteoblasts by directly targeting Osterix. Mol Biol Cell. 2011;22(21):3955-61.

90. Li H, Xie H, Liu W, Hu R, Huang B, Tan YF, et al. A novel microRNA targeting HDAC5 regulates osteoblast differentiation in mice and contributes to primary osteoporosis in humans. J Clin Invest. 2009;119(12):3666-77.

91. Qureshi AT, Monroe WT, Dasa V, Gimble JM, Hayes DJ. miR148b-nanoparticle conjugates for light mediated osteogenesis of human adipose stromal/stem cells. Biomaterials. 2013;34(31): 7799-810. This study illustrates the technique of photoactivation to release miRNA, with potential clinical applications to control release of miRNA within skeletal tissues.

92. Schoolmeesters A, Eklund T, Leake D, Vermeulen A, Smith Q, Force Aldred S, et al. Functional profiling reveals critical role for miRNA in differentiation of human mesenchymal stem cells. PLoS One. 2009;4(5):e5605. 